\title{
Exploring the fear of contracting hiv/aids among trauma nurses in the province of Kwazulu-Natal
}

\author{
BP Ncama, (M.Cur), School of Nursing, University of Natal \\ LR Uys, (D.Soc.Sc), School of Nursing, University of Natal
}

\section{Abstract}

A qualitative study, using phenomenology as an approach was conducted. The title of the study was

"Exploring the fear of contracting HIV/AIDS among trauma nurses in the province of Kwazulu-Natal". Participants were selected on the basis of category (registered nurses), workplace (level one trauma units), and work experience (six months experience in a trauma unit). Twelve nurses participated in the study, six from the state institutions and six from the private institutions.

The objectives of the study were to explore the fear of contracting HIV/AIDS, its effect on their personal/ working lives and how they coped with it.

The findings of the study revealed that trauma nurses per- ceived themselves to be at risk of acquiring HIV/AIDS from their working environment despite the available precautionary measures. Needlestick injuries appeared to be the main source of fear. They used different coping and defence mechanisms effectively to cope with this fear of contracting HIV and none were in any emotional crisis.

Education at different levels and development of support networks has been recommended as the key strategies to decrease these fears. Other recommendations include improving the quality and availability of protective materials and equipment, making HIV/AIDS a notifiable disease as well as improving general and specific beliefs that increase coping.

\section{Introduction and background to the study}

AIDS and HIV have been described as one of the greatest challenges of the twentieth century to public health. UNAIDS report indicated that about 40 million people were living with HIV/AIDS worldwide, with about 28.5 million people living SubSaharan Africa (UNAIDS, 2002). In South Africa, in a population of about 43 million people, it is estimated that 5 million are infected with HIV, which translates to about 1 in every 9 people (UNAIDS, 2002). Statistics indicate that KwaZulu Natal is the worst affected province with a $37.8 \%$ infection rate among antenatal clinics attendees (Dorrington, Bradshaw and Budlender, 2002).

On the other hand unnatural events such as assaults, motor vehicle accidents, drowning and other trauma- related incidents have been reported as the leading cause of death in South Africa between the years 1997 and 2001 (Statistics South Africa, 2002, p.5). In KwaZulu Natal trauma resulting from political, criminal, occupational or domestic violence; road or sports accidents, and suicide has claimed a considerable number of lives, caused extensive disability and loss of potential manhours. Trauma personnel are especially at risk of HIV infection because of greater incidence of HIV seroprevalence in trauma patients and other blood-borne infections. The presence of free flowing blood, the rush to save lives of trauma victims and the frequent need for invasive procedures in seriously traumatised patients make the trauma workers even more susceptible to HIV infection.

Although there are prescribed precautions to prevent infection to caregivers, risk still exists, especially through needle stick injuries, and is estimated at $0.3 \%$ (McCarthy, Ssali, Bednarsh, Jorge, Wangrangsimakul, Page-Shafer, 2002; Van der Ryst, 1999). As of June 2001, occupational exposure to HIV had resulted in 57 documented cases of HIV seroconversion among healthcare personnel in the United States (Centre for Disease Control, 2001). Although this is relatively low, research shows that the fear of contagion remains a concern among nurses and other health care workers involved in caring for HIV/AIDS patients (Sherman, 2000: 2; Uwakwe. 2000:5; MCCann and Sharkey 1998:2, Kemppainen, Dubbert and McWilliams, 1996; Wang and Paterson, 1996).

The statistics of HIV/AIDS presented in the previous section pose a challenge to health care workers who are expected to care for the HIV/AIDS patients indiscriminately. At present there has been no internationally accepted definitive treatment for HIV/AIDS or vaccine. Health care workers rely on preventative measures to protect themselves against the virus. A number of studies have indicated that hospital nurses were the most exposed groups, and underreporting was common (Moloughney, 2001:2; : 1, Williams and McCahon, 2001; Knight 
\& Bordsworth, 1998:2). Preventative measures include some of the following (Center for Disease Control, 2001):

- Universal Precautions which include the following:

- Wearing protective clothing during handling of body fluids and infected material e.g. Gloves.

- Handwashing.

- Covering of cuts and avoiding HIV infected patients by healthcare workers with weeping dermatitis

- Careful handling and proper disposal of sharps during and after use, e.g. injection needles

- Proper human wastes cleaning, disinfection and proper disposal of equipment.

- Education and training of staff on preventive measures, use of protective material, making the protective material available and development of protocols about acci dental exposure and prophylactic treatment.

- $\quad$ Limiting high-risk procedures e.g. mouth to mouth resuscitation.

- $\quad$ Avoiding needle stick injury through appropriate precautions and education.

- $\quad$ Post-exposure prophylaxis.

Some literature has been published on the subject of health care workers fear of AIDS, and there has been a strong indication that it exists even though they know about universal precautions (Uwakwe, 2000:2; Sherman, 2000:2; McCann and Sharkey 1998:2; Wang \& Paterson, 1996). Other studies have shown that some nurses wanted to have a choice whether to care or not to care for HIV positive patients, while other nurses exhibited negative attitudes towards caring for HIV positive patients (Mbanya, Zebase, Kengne, Minkoulou, Awah and Beures, 2001:5; Sherman, 2000:2; Wang \& Paterson, 1996). Nurses' fear of contracting HIV has been shown to decrease their willingness to care for HIV positive patients and this can in turn compromise the quality of care (Lohramn, Välimăki, Suominen, Dassen, and Peate, 2000:1). In some countries, continuous education and action research projects have been reported as beneficial in developing confidence to care for patients with AIDS (Pratt, Pellowe, Juvekar, Potdar, Weston, Joykutty, Robinson and Loveday, 2001 :6 ; Mbanya, et.al 2001 :7), but other studies have reported educational programmes as not effective in changing nurses' attitudes and fears.

Most of the research in this area has been conducted in the United States, some in Europe and other developed countries. Very little research has come from developing countries, especially Africa. Välimäki, Suominem and Peate (1998:3) also argue that the main focus of empirical research conducted in this area has been amongst the general public and students with little attention to practising nurses.

The fear of contracting HIV could also be present in other South African nurses even if it is not expressed, especially in high- risk areas such as trauma and theatres. No study of a similar nature was identified in the province of KwaZulu-Natal. This is what prompted the researcher to undertake this study.

\section{Research questions}

-What have been the experiences of trauma and emergency room nurses, and what are their fears about contracting HIV/ AIDS in KwaZulu-Natal ?

-How do trauma and emergency room nurses cope with the fear of contracting HIV/AIDS ?

\section{Methodology}

Qualitative study using the phenomenological approach. The rationale for choosing this qualitative approach was based on the fact that most research of this nature has been conducted using quantitative methods, which might fail to give the interpretation of the lived experiences and the fear of contracting HIV. Välimäki et. al (1998:3) also argue that the main focus of empirical research conducted in this area has been conducted using questionnaires which have been developed by the research team, and had mainly involved large samples. A phenomenological approach focuses on describing the experiences as they are lived within a particular situation (Burns and Grove, 2001; Polit and Hungler, 2001). The researcher was interested in studying the phenomenon of fear of contracting HIV, which is a lived experience and therefore the phenomenological approach seemed more appropriate.

\section{Population and selection of participants}

Purposive selection of participants from two urban area level1 trauma units was done. They were selected on the basis of category (registered nurses), workplace (level-1 trauma units) and experience (should have worked there for at least six months). This study concentrated on urban areas since they were the ones that had level-1trauma units.

\section{Data collection and analysis}

An interview guide was developed, but the researcher was directed by the participants responses on the progress of the interview, and could probe or follow up information that came to the fore. Two interviews per participant were conducted. During the first interview the researcher endeavoured to establish a trusting relationship with the participants, explained the purpose of the study and explored the phenomenon under study. The emergency nurses' conceptualisation of the fear of contracting HIV/AIDS was explored, its effects on their everyday working and personal lives, as well as their coping strategies. The second interview reflected on the data obtained from the first interview, clarified misunderstandings or misconceptions, asked participants for suggestions and solutions from their own views and exited based on the principle of data saturation.

\section{Measures used to ensure validity of the study}

Bracketing- The researcher undertook the process of acknowledging and revealing her thoughts about the topic by documenting them. The researcher is a trauma nurse by training, and has worked in trauma settings before, although no longer working in these settings. It is her opinion that trauma nurses have the fear of contracting HIV/AIDS as they work. This is also based on her previous interactions with the trauma nurses and this is what prompted this study. This information was 
Theory of coping

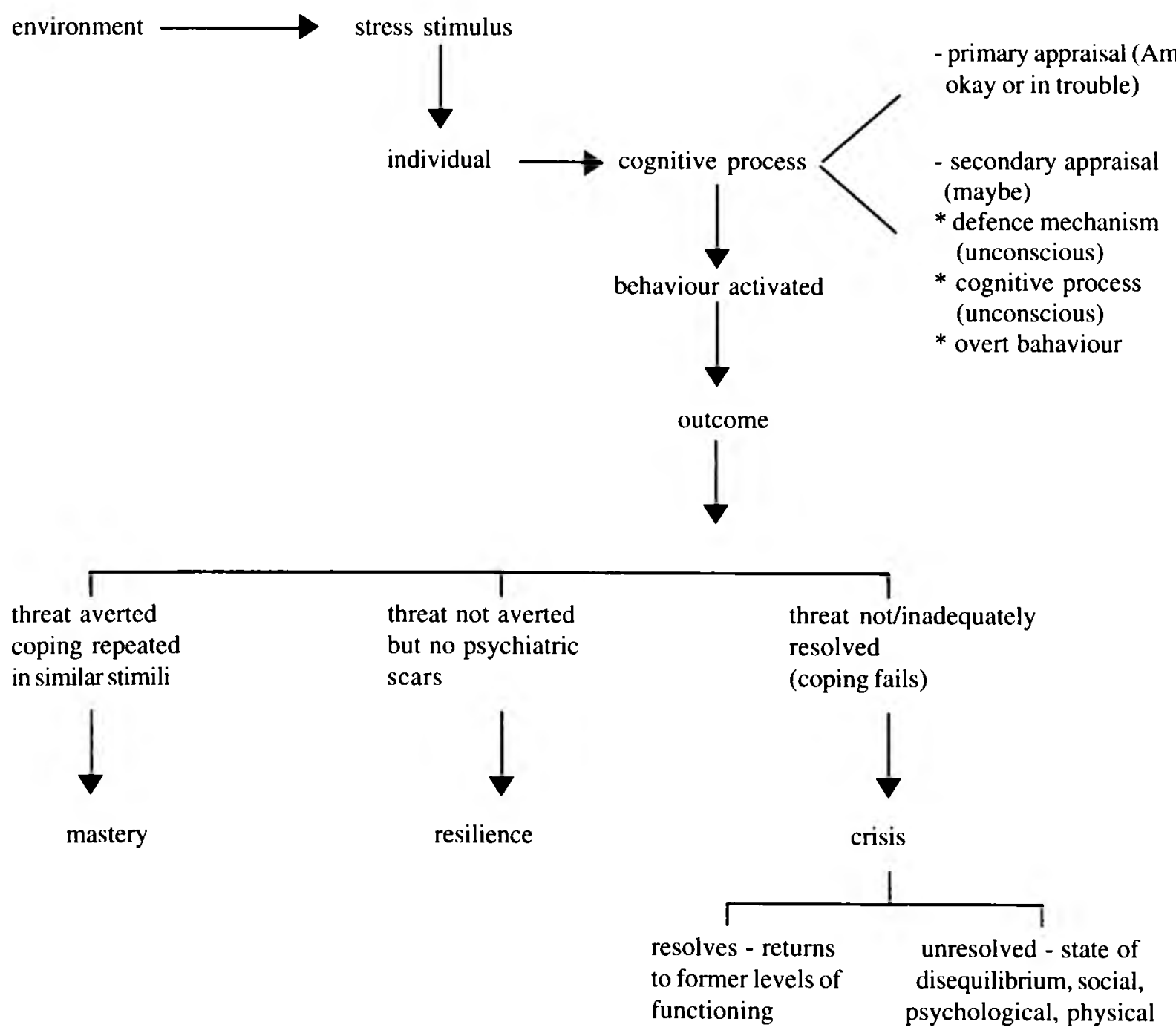

used to keep reminding the researcher to listen to what is real to participants than what is real to the researcher (Streubert and Carpenter, 1999).

Trustworthiness and authenticity of data- This was achieved mainly through member checks. Data was analysed and a short summary made from each participant's responses and referred back to the participants to validate it and add any new information to it and that formed the starting point of the second interviews

Expert Validation- The study was conducted under the guidance and supervision of an experienced researcher. She listened to the tapes and also looked at the transcribed data as well as the analysis.

\section{Pilot Study}

Two participants were selected for the targeted population on a similar basis as for the main study. The pilot study was necessary to establish any ambiguity in the questions, and to check whether data produced was relevant to the research questions. The results of the pilot formed part of the actual study itself. The reason for including them in the study was that in qualitative research all the data is valuable, and it should be used towards the study, not separated from it (Polit and Hungler, 2001).

\section{Ethical issues and gaining access}

Participants' permission was obtained and the recordings destroyed after transcribing to ensure confidentiality. Pseudonyms were used to ensure anonymity. Permission was obtained from the KwaZulu Natal Head of Health Services for State hospital interviews. Permission to interview staff in private hospitals was obtained from the management of identified hospitals. Participants had a right to withdraw from the study at any point and time if they wished to do so.

\section{Presentation of results}

The theory of coping was chosen to guide this study as it deals with fear, which is also described as a primary coping response to threats (Lazarus, 1966). Since this study is investigating the fear of contracting HIV/ AIDS and how nurses are handling it (coping), it seemed appropriate that results are presented according to this framework.

Categories were formulated based on the theoretical frame- 
work for presentation of results. These were operationalised as follows:

Primary appraisal: Refers to the significance of HIV /AIDS as perceived by the trauma nurses, the history of its significance, how it has evolved over the years and its significance in their working and personal lives.

Secondary appraisal: Refers to the assessment and use of coping strategies and resources and includes the defence mechanisms employed and the behavioural changes that have taken place to adapt to the threat of HIV/AIDS in their workplace.

Reappraisal: Refers to the trauma nurses' reaction to the threat of HIV/AIDS in the workplace and their families' fear, as well as their reaction to, and knowledge about, issues pertaining to seroconversion.

Outcomes: Refers to the outcomes of the overt behaviours, cognitive behaviours, and defence mechanisms activated and instituted and will include mastery, resiliency and crisis.

\section{Primary appraisal (significance) Previous perceptions about HIV/AIDS}

Most nurses interviewed admitted that fear was their initial response when the threat of HIV/AIDS was first publicised. At that stage they were scared of even coming near patients who had tested HIV positive or diagnosed with AIDS, as well as coming into contact with bloods and body fluids. They attributed this to lack of knowledge and understanding of the disease process itself, as well as the mode of spread of HIV and the myths about the spread of HIV/AIDS at that stage. The biggest fear also came from the fact that there was no treatment for HIV/AIDS and they thought of it as a death sentence. They described their initial feelings as being in a state of shock, confusion and apprehension. They were also concerned about whether they had already contracted HIV/AIDS because of previous unprotected exposures before HIV/AIDS was publicised. One nurse commented as follows:

I was placed in casualty and trauma departments in the early eighties when HIV/AIDS was not a common thing to know, and being at the government hospital, we dealt with gin shots, stabbings, taxi violence victims, you know what I mean and we just worked with bare hands only with no system of gowns, masks and gloves. When I look back now at the way we worked then, I thank God I am negative, very often we had cuts on our hands and because I did diving, I got a lot of them from diving, because you are under the sea and you get cuts from the coral, and we did not even bother covering them, we just worked with our bare hands and no gloves and we did not even know who was positive and who was not. I have been exposed badly.

\section{Perception about possibility of contracting HIV in the workplace}

It appeared that the fear of contracting HIV in the workplace still exists despite the available precautionary measures. They responded that it was due to the fact that they handled blood and body fluids most of the time and worked in a haste. The needlestick injury was their main concern as most felt they could not always avoid it. One nurse commented as follows: "Although we treat everybody as HIV positive, there is this needlestick injury which you cannot always avoid and that worries me".

They also expressed concern about the reliability of the protective equipment, especially the gloves and felt that the quality be improved to offer maximum protection against the virus. The following are some of the comments made:

“.... You know with the gloves we use, they are not 100\% safe, so you find that sometimes when you remove them they are perforated and that's when the fear comes ....."

\section{Family concern}

It appeared that the significance of HIV/AIDS went beyond the working environment to include their concern about family. Nurses did not only see themselves as at risk, but were also worried about the possibility of contracting HIV/AIDS at work and then transmitting it to their partners or offsprings. One nurse commented as follows:

".....you know especially if you have family and stuff like that you worry for them and about them".

\section{Secondary appraisal (coping resources) \\ Cognitive and defence mechanisms}

It appeared that the nurses had developed different coping and defence mechanisms to deal

with their fear of contracting HIV in the workplace. The following mechanisms were identified from the nurses responses:

(a) Humour - Some nurses used humour to express their fear when talking about HIV/AIDS, but without causing each other discomforts. This is reflected in the following statements:

"I said to her you and I will be dead after 10 years because they say the incubation period is about 5 to 10 years and we both laughed". "Sometimes we talk and joke about it..."

(b) Suppression - Some nurses avoided thinking about the possibility of contracting HIV as they worked but often thought about it later. This is reflected in the following statements:

"It's not a good thing to think about all the time."

"No, its not good to think about it when you are working, because you might end up panicking and pricking yourself, so you just take it out of your mind and apply your universal precautions."

(c) Altruism- Some nurses said that they were more sympathetic and understanding towards HIV/AIDS patients and had become more caring towards them. This is reflected in the following statement: "we just think about this poor patient"

(d) Minimizing- Some nurses used minimizing as a defence mechanism and equated HIV/AIDS to any other infectious conditions that they can contract at work, although the threat of HIV/AIDS is higher than those other conditions which can be treated. One nurse commented as follows:

Working in trauma, we are aware of it; it's not just HIV that we can contract, it's TB, it's whatever you can get, you can get chicken pox, measles, mumps, or anything from a patient, and that's just in the line of duty

(e) Anger

Anger was mainly directed towards the management who 
viewed needlestick injuries as caused by negligence and were therefore unsupportive. Anger was also directed at patients whose behaviour put them at high risk for HIV/AIDS such as womanisers and sex workers. This is evident the following statement from a nurse who sustained a needlestick injury while attending a patient known for promiscuity and practising unsafe sex:

"I was so upset about the whole thing because of his behaviour as well, the fact that there was so much talk about HIVI AIDS and there were still people who were fooling around like that , so I was really very upset and angry nith him."

\section{(f) Displacement}

It appeared that the employer was mainly blamed for the number of accidental exposures to HIV, for not providing adequate protective equipment, andfor viewing accidental occupational exposure to HIV as negligence. While most of the allegations could be accepted as appropriate, they could also be viewed as displacement, with the employer becoming the scapegoat for the incidents that could have been prevented by applying the necessary universal precautions properly. One nurse commented as follows:

Exactly, when you get a person that is employed as a painter and he falls from the scaffolding, the employer must take responsibility because it is his work and there is a likelihood that he may fall as a result of his job, so with the nature of our jobs there is a likelihood that we will get pricked.

\section{Behavioural}

(a) Influence of fear on work performance

There were mixed feelings on this aspect. Some felt the fear of contracting HIV had no influence on the manner in which they performed their duties. All of them maintained that they wanted to continue nursing and were not going to change their profession because of the fear of contracting HIV in the workplace. This could be attributed to the fact that job opportunities are scarce, and people need an income to survive and also to the fact that some chose nursing because they liked it.

\section{Positive influences}

It appeared that the fear of contracting HIV has increased the application and efficiency of universal precautions.

It also appeared that a caring attitude had increased as most nurses reported that they felt sorry for the HIV positive patients and were quite sympathetic towards them, because there was no cure for HIV/AIDS at this stage. This also increased confidentiality and professional secrecy, as most nurses felt these patients need not be exposed. This is evidenced by the following statement:

"we have become more cautious especially with the needlestick injury prevention".

\section{Negative influences}

It appeared that treatment is sometimes delayed as a result of the fear of contracting HIV. Restless patients are expected to settle first before any major intervention like suturing is done. The process of gloving up, putting on visors and aprons does also cause a few seconds' delay, although it is necessary. Some nurses made the following comments:

"there are these rules now, that if a patient is either drunk or restless let him settle before you can suture him, since we do a lot of suturing here, and in the meantime you apply a pressure bandage and arrest haemorrhage, because that is when most accidental needlestick injuries happen, that is when dealing with restless and drunk patients".

"Like I have talked about gloves, ..... although I am aw'are that in the process it might delay the patient's treatment".

\section{Perceptions towards making HIV a notifiable disease}

There were mixed feelings on this aspect. These can further be subcategorised as follows:

\section{Supportive}

Some participants supported the idea of making AIDS a notifiable disease, and felt that this would increase awareness and influence behavioural changes and possibly remove the stigma attached to HIV and AIDS. They also felt that it would decrease the fear of contracting HIV in the workplace by increasing awareness, and thus the efficiency, of universal precautions, and strengthen preventative measures against HIV and AIDS even in the nurses' personal lives. One nurse is quoted as saying "Awareness is not so effective if there is secrecy" Against

Some nurses felt it violated a patient's right to privacy. They also believed that it was unnecessary, as there was no available treatment at present for these patients. They also felt it would not have any influence on the fear of contracting HIV/ AIDS in the workplace as the nurses should treat all patients as HIV positive, irrespective of their HIV status. One nurse is quoted as saying, "It infringes on the patient's right to privacy and confidentiality"

\section{The role of education and HIV/AIDS counselling courses}

The widespread education about HIV/AIDS, as well as the inservice education occasionally presented to staff, has increased the nurses' understanding about HIV/AIDS and thereby alleviated some of their fears. AIDS counselling courses have also played an important role in decreasing the fear of contracting HIV in the workplace. Education alleviated, but did not completely eliminate the fear of contracting HIV/AIDS in the workplace. One nurse is quoted as saying:

"Before, it used to worry us, but now that we are well educated about HIV and AIDS, doing the courses and the AIDS counselling courses, our fears have been alleviated from that knowledge gained, and from the fact that we treat all our outpatients as positive".

\section{Availability and accessibility of counselling}

Most nurses expressed concern that the availability and accessibility of post accidental exposure counselling was only immediate, and no follow up mechanism was in place especially because of the window period. They felt that counselling sessions should be scheduled to go on until enough proof has been obtained that the individual did not seroconvert. "Counselling, it's a one time thing, you are told you are HIV positive and counselled for the first time, that's it you go home and that is all, nobody looks after you then, you are on your own."

\section{Anticipation}

Some nurses had made realistic plans for the future with regard to HIV/AIDS. Some had taken policies that would cover them 
in the event of seroconversion from HIV negative to a positive status. . One nurse is quoted as saying "Some of us have taken our own individual policies against AIDS/HIV"

\section{Activating spiritual powers}

Some nurses expressed feelings of helplessness, saying that they would leave everything to God, even with regard to the possibility of accidental exposure to HIV. One nurse is quoted as saying, "just give this thing to God, don't you worry about it."

\section{Reappraisal (own reaction) Conceptualization or description of the fear of contracting HIV/AIDS}

The fear was mainly described as a feeling of anxiety and a worry when they faced with an HIV positive

patient, or any situation that reminds them of the possibility of getting HIV at work. Some nurses

described it as a feeling of tenseness, others said they were bothered by the knowledge that they were in

danger of contracting HIV in the course of their work.

Others, who reported that they did not have any fear of contracting HIV at work.

They also felt that nurses should focus on preventing sexual exposure to HIV, rather than

worry about occupational exposure in which the risk was so minimal. Some nurses commented as follows:

"The fear is not there all the time, it comes and goes, like when you see a bleeding patient

and you think that he might be HIV positive"

"Its an anxious feeling that you get when you think that as I am working here there is a

possibility of accidental occupational exposure".

\section{Family's fear}

All nurses interviewed admitted that their families were concerned about the nature of their work in the presence of high HIV prevalence. Husbands, boyfriends and partners were the people who were mostly concerned, some reported poor support from them in cases of needlestick injuries, and some were even ostracised by them. The partners were concerned about the possibility of their loved ones contracting HIV at work and transmitting it to them. It also appeared that husbands were more sympathetic and supportive as compared to boyfriends. The reason given for the family concerns was mainly ignorance. These are some of the comments made:

"You know there is this girl I worked with, when she had a needlestick injury, her boyfriend wanted nothing to do with her until she could prove that she was negative and he wanted to see all the results until about six months later..."

"My husband supported me throughout that period..."

\section{Knowledge of company policy and financial issues involved in case of occupational exposure to HIV}

Nurses in both the State and private hospitals were all aware of the immediate management of the needlestick injury but did not know the long-term implications and management. They were familiar with the policy and procedure to follow immediately after needlestick injury, or any accidental exposure to HIV-infected blood and body fluids. About the long term management and implications one nurse commented as follows:

"No one we know has ever seroconverted, so we just do not know what happens"

Nurses in private hospitals have to pay for HIV investigation and treatment post accidental occupational exposure whereas in state hospitals this was provided as a free service. They also did not know if accidental occupational exposure to HIV was covered by the above mentioned Act or not. They were not aware of whether they could claim back the money they paid for blood tests and treatment. State nurses seemed to regard the accidental occupational exposure to HIV as covered by the W.C.A., although they were unsure about the procedure for compensation in case of seroconversion.

\section{Outcomes of the behaviour}

\section{Mastery}

All nurses had developed their own standards of mastering the situation, which were the result of different coping and defence mechanisms, including the practical efforts to lessen their susceptibility to accidental exposure.

\section{Resiliency}

Resiliency was evident in those nurses who had been accidentally exposed to HIV infected blood and body fluids, especially through the needlestick injuries. They had used coping mechanisms appropriately and repeatedly in their situations and had recovered their equilibrium. This was evident in the following comment:

It's been two years since the needlestick injury and I had a baby a year ago and everything was fine, we were all tested and we were negative and I really feel much better about the whole incident now.

\section{Crisis}

Nobody was in a crisis.

\section{Discussion and recommendations}

It appeared that the fear of contracting HIV/AIDS among trauma nurses still exists, despite available precautionary measures. Nurses felt these were not sufficient, or their quality was not up to acceptable standards to prevent contamination, e.g. gloves that tear easily. Weiss (1997) argued that the success of universal precautions has been limited, especially with regard to percutaneous injuries because gloves fail to prevent penetrating injuries and tear easily.

This fear also appeared to go beyond their working environment to their families. They were concerned that

they might contract HIV and transmit it to their partners and offspring, and so were the partners. No literature could be identified in relation to this issue.

The fear of contracting HIV seemed to have increased the application of universal precautions in preventing needlestick 
injuries. There was dissatisfaction with the employer and management support.

Education about HIV/AIDS, as well as AIDS counselling courses, appeared to play a major role in decreasing the fear of contracting HIV and AIDS in the workplace, but did not completely eliminate it. This confirms the findings of a study conducted in KwaZulu-Natal among midwives by Mabaso (1992) that knowledge increases the application of universal precautions. They used different coping and defence mechanisms effectively to cope with the fear of contracting HIV and none were in a crisis as the result of this fear. Resiliency was evident among those nurses who had suffered needlestick injuries and said they had bounced back into equilibrium.

The following are the recommendations that came out of this study:

\section{Education}

\section{In-service education}

This should increase and focus not only on the immediate management post accidental occupational exposure to HIV, but should include long- term implications of seroconversion from HIV negative to positive. There should be some means of testing the nurses' knowledge and understanding of the subject. This could be done by the infection control department and can absolve the employer of some responsibility. Education should also include families and nurses' partners, and could be done by providing them with pamphlets. Nurses' organisations should also take responsibility in educating their constituency, especially about their legal rights and the provisions of the different acts and laws that are applicable. As new information comes to the fore, ways of making sure that the new developments and trends filter down to nurses should be developed.

\section{AIDS counselling courses}

It would be ideal if all nurses working with HIV positive patients are sent for AIDS counselling courses to prepare them to deal with the epidemic of AIDS, this could also decrease their fears and improve their willingness to work with HIV positive patients. There should also be follow-up courses to ensure continuity and dissemination of new information.

\section{Increased availability and improvement in protective measures}

Protective material should be made available to those who deal with blood and body fluids, quality should be checked to ensure that it is up to standard. More technologically advanced universal precautionary instruments should be made available and accessible to those who handle body fluids and blood e.g. availability of magnets to pick up dropped sharps and puncture- resistant sharps containers.

\section{Improving staff morale}

Management can improve staff morale through making universal precautions material and prophylaxis available and accessible to staff members and increasing access to counseling.

\section{Development of support networks}

Development of forums or networks where nurses can share information on issues pertaining to the care of HIV positive patients within their hospitals and outside, and allow debriefing would be useful.

\section{Reinforcing positive general and specific beliefs}

Garland \& Bush (1982) also advocate the re-inforcement of general and specific beliefs that make people think that they can master most situations e.g. spiritual trusting

\section{Conclusion}

The working patterns in trauma units should change to reflect changes in time, experience, attitudes and current issues, such as HIV/AIDS. For nurses to be able to function properly in combating the threat of HIV/AIDS, their concerns and fears must be heard, and interventions planned to address them.

\section{References}

BRISTOL-MYERS SQUIBB, 1999: Secure the future: Care and support for women and children with HIV/AIDS. Nursing Update. $23(6)$ : 19-20.

BROWN \& BROWN, J 1988: The third international conference on AIDS: risk of AIDS in health care workers. Nursing Management 19 (3): 33-35.

CENTRE FOR DISEASE CONTROL 2001: Preventing Occupational HIV Transmission to Healthcare Personnel. Available at http://www.cdc.gov/hiv/pubs/facts/hcwprev.htm

DORRINGTON, R; BRADSHAW, D AND BUDLENDER, D 2002: HIV/AIDS profile in the provinces of South Africa. Indicators for 2002. The Centre for Actuarial Research, Medical Research Council's Burden of Disease Research Unit, and the Acturial Society of South Africa. Centre for Actuarial Research. University of Cape Town.

EDWARDS, S M; WILLIAMS, J C AND MCCAHON, R A 2001: Universal Precautions at cardiac arrests. Anaesthesia. 56(4): 378-379.

GARLAND, L M \& BUSH, T 1982: Coping behaviours and nursing. Georgia: Reston Publishing Company.

LOHRAMANN, C; VÄLIMÄKI, M; SUOMINEN, T; MUINONNEN, U; DASSEN, T; AND PEATE, I 2000: German nursing students' knowledge and attittudes to HIV/AIDS: two decades after the first AIDS cases. Journal of Advanced Nursing 31(3): 696-703.

KEMPPAINEN, J K; DUBBERT, PM \& MCWILLIAMS, P 1996: Effects of group discussion and guided patient care experience on nurses attitudes towards care of patients with AIDS. Journal of Advanced Nursing. 24: 296-302.

KNIGHT, V M \& BODSWORTH, N J 1998: Perceptions and practice of universal blood and body fluid precautions by registered nurses at a Sydney teaching hospital. Journal of Advanced Nursing. 27(4): 746-751.

MABASO, Z M 1992: The utilisation of universal precautions against HIV infection by midwives in the labour ward of a 
Pietermaritzburg hospital. Master thesis. Unpublished document. University of Natal, Nursing Department.

MBANYA, DN; ZEBASE, R; KENGNE, A P; MINKOULOU, EM; AWAH, P AND BEURE 2001: Knowledge, attittudes and practices of nursing staff in a rural hospital in Cameroon: how much does the health care provider know about human immunodeficiencey virus/ acquired immune deficiency syndrome? International Nursing Review. 48(4): 241-249.

MCCANN, TV \& SHARKEY,M 1998: Educational intervention with international nurses and changes in knowledge, attitudes and willingness to provide care to patients with HIV/AIDS. Journal of Advanced Nursing. 27(2): 267-273.

MOLOUGHNEY, B W 2001: Transmission and post-exposure management of blood-borne virus infections in the health care setting: where are we now? Canadian Medical Association and its Licencesors. 21. Aug.: 445-451.

MULDER, D \& COLLEGUES 1994: HIV and AIDS: fact not myth. AIDS Action 27(6).

PRATT R, J; PELLOWE, CM; JUVEKAR,S K; POTDAR.M S; WFSTON, A J; JOYKUTTY, A; ROBINSON, N; LOVEDAY, H P 2001: Kaleidoscope: A 5- year action research project to develop nursing confidence in caring for patients with HIV disease in West India. International Nursing Review. 48(3) 164173.

ROBINSON, N 1998; People with AIDS: who cares? Journal of Advanced Nursing, 28, 4,p. 771-778.

Sherman D. W. (2000). Experiences of AIDS-dedicated nurses in alleviating the stress of AIDS caregiving. Journal of Advanced Nursing. 31(6): p1501-1508.

SMITH, A N 1999: King Edward VIII Hospital Antenatal clinic HIV prevalence. Department of Virology. University of Natal, Unpublished documents.

STATISTICS SOUTH AFRICA 2002: Causes of Death in South Africa 1997-2001. Advanced release of recorded causes of death. Available at http:www. Statssa.org.za

UWAKWE, CBU 2000: Systematized HIV/AIDS education for student nurses at the University of Ibadan, Nigeria: impact on knowledge, attittudes, and compliance with universal precautions. Journal of Advanced Nursing. 32(2): 416-425.

VÄLIMÄKI, M; SUOMINEM, T \& PEATE, I 1998: Attitudes of professionals, students and the general public to HIV/AIDS and people with HIV/AIDS: a review of the research. Journal of Advanced Nursing. 27(4): 752-759.

VAN DER MERWE, A 1998: Private Health Care. Hospital Association of South Africa. Greenside: Wilbury and Claymore.

VAN DER RYST, E 1999: Needle stick-injuries-prevention of the transmission of hepatitis B, C, and HIV. Trauma and Emergency Medicine, 16(1): 12-17.

WANG, J F \& PATERSON, J 1996: Using factor analysis to explore nurses fear of AIDS in the United States of America.
Journal of Advanced Nursing. 24: 287-295.

WEISS, S H 1997: Risks and issues for the health care worker. Medical Clinics of North America. 76(1): 267-277. 